\title{
BMJ Open Community health workers involvement in preventative care in primary healthcare: a systematic scoping review
}

\author{
Nila Sharma, Elizabeth Harris, Jane Lloyd, Sabuj Kanti Mistry, Mark Harris
}

To cite: Sharma N, Harris E, Lloyd J, et al. Community health workers involvement in preventative care in primary healthcare: a systematic scoping review. BMJ Open 2019;9:e031666. doi:10.1136/ bmjopen-2019-031666

- Prepublication history and additional material for this paper are available online. To view these files, please visit the journal online (http://dx.doi. org/10.1136/bmjopen-2019031666).

Received 14 May 2019 Revised 04 November 2019 Accepted 25 November 2019

Check for updates

(c) Author(s) (or their employer(s)) 2019. Re-use permitted under CC BY-NC. No commercial re-use. See rights and permissions. Published by BMJ.

Centre for Primary Health Care and Equity, University of New South Wales, Sydney, New South Wales, Australia

Correspondence to

Professor Mark Harris;

m.f.harris@unsw.edu.au

\section{ABSTRACT}

Objectives To review effective models of community health worker (CHW) involvement in preventive care for disadvantaged culturally and linguistically diverse (CALD) patients in primary healthcare (PHC) that may be applicable to the Australian context.

Design Systematic scoping review.

Data sources The studies were gathered through searching Medline, EMBASE, EMCARE, PsycINFO, CINAHL and online portals of relevant organisations.

Eligibility criteria All selected studies were original research studies which essentially evaluated preventive intervention undertake by $\mathrm{CHWs}$ in PHC. The intervened population were adults with or without diagnosed chronic health disease, culturally and linguistically diverse, or vulnerable due to geographic, economic and/or cultural characteristics that impede or compromise their access to healthcare.

Data extraction and synthesis Data extraction was undertaken systematically in an excel spreadsheet while the findings were synthesised in a narrative manner. The quality appraisal of the selected studies was performed using effective public health practice project quality assessment tool.

Results A total of 1066 articles were identified during the initial search of six bibliographic databases. After screening the title, abstract and full text, 37 articles met the selection and methodological criteria and underwent data extraction. A high-quality evidence-base supporting the positive impact of CHWs supporting patients' access to healthcare and influencing positive behaviour change was found. Positive impacts of CHW interventions included improvements in clinical disease indicators, screening rates and behavioural change. Education-focused interventions were more effective in improving patient behaviour, whereas navigation interventions were most effective in improving access to services. Implementation was enhanced by cultural and linguistic congruence and specific training of CHWs in the intervention but reduced by short duration interventions, dropouts and poor adherence of patients.

Conclusion The evidence generated from this systematic scoping review demonstrates the contribution of $\mathrm{CHWs}$ to improving access to preventive care for patients from CALD and disadvantaged backgrounds by providing both education and navigational interventions. More research is needed on CHW training and the incorporation of CHWs into primary health care (PHC) teams.
Strengths and limitations of this study

- This systematic scoping review was conducted in accordance with the A Measurement Tool to Assess Systematic Review standards. Effective public health practice project quality assessment tool was used for quality assessment of the identified studies.

- Six bibliographic databases were searched using a basic search strategy that were modified as per the database requirements.

- Reliability of the study selection, data extraction and rating of the study quality was ensured by four reviewers.

- The studies were heterogeneous in their methods and outcomes evaluated.

\section{INTRODUCTION}

The burden of disease due to chronic conditions is increasing in Australia and globally. ${ }^{1}$ Primary healthcare (PHC) has an important role in the prevention and management of these conditions. ${ }^{2}$ Often this requires the management of behavioural and physiological risk factors that are within the scope of PHC practice. ${ }^{3}$ However, there are concerns about the capacity of PHC providers to deal with this additional workload. ${ }^{4}$ This has given rise to calls for greater sharing of responsibility within the PHC team and extending the team to include new categories of workers. ${ }^{5}$

The burden of chronic disease is not shared equally among the population. Those in the lowest fifth of the Australian population by socioeconomic position have worse prevalence and mortality rates for most long-term conditions than those with a higher socioeconomic status. ${ }^{6}$ However, there are structural and systematic barriers to access preventive care for low socioeconomic groups and certain ethnic groups such as cost, poor integration of care between providers and services and insufficient access to interpreters or bilingual workers. ${ }^{7-9}$ They may also have 
low health literacy which in turn is associated poorer uptake of preventive care and preventive behaviours. ${ }^{10-13}$ Reducing barriers to preventive care in PHC is necessary in order to reduce healthcare disparities, mortality, morbidity, hospitalisation rates and healthcare cost. ${ }^{14} 15$

Community health workers (CHWs) are members of a community whose role focuses on providing individual patients support. CHWs have the potential to improve access to preventive care and contribute to reduced hospitalisation and rehospitalisation rates among disadvantaged populations.

With this review we sought to identify effective models of CHW involvement in preventive care in PHC, especially for culturally and linguistically diverse (CALD) patients.

\section{Research question}

The objective of this review was to assess the effectiveness of models of CHW involvement in preventive care for disadvantaged patients in PHC that could be applicable to Australian context. We also sought to describe the implementation of these models and understand the context of CHW interventions, in addition to their effectiveness in improving health and health service outcomes.

CHWs are frontline health workers who have numerous job titles including CHWs; lay health workers; health promotors; health navigators. The definitions of CHWs are equally varied. For this study, we chose the definition developed by the American Public Health Association: 'community health workers (CHWs) are frontline public health workers who are trusted members of and/ or have an unusually close understanding of the community served. This trusting relationship enables CHWs to serve as a liaison/link/intermediary between health/ social services and the community to facilitate access to services and improve the quality and cultural competence of service delivery. CHWs also build individual and community capacity by increasing health knowledge and self-sufficiency through a range of activities such as outreach, community education, informal counselling, social support and advocacy'. ${ }^{16}$

Disease prevention, includes specific, populationbased and individual-based interventions for primary and secondary (early detection) prevention, which aim to minimise the burden of disease and associated risk factors. ${ }^{17}$

\section{METHODS}

Our review was guided by the standard principles of systematic scoping review, ${ }^{18-20}$ and the protocol for the review was published in the website of Centre for Primary Health Care and Equity, UNSW Sydney (https://cphce. unsw.edu.au/research/health-system-integration-andprimary-health-care-development/community-healthworkers). It has been recognised that social problems and public health interventions are complex. Therefore, a wide variety of study designs may be used in the evaluation of public health interventions ranging from

\begin{tabular}{|c|c|c|}
\hline Database & Date of search & No of results \\
\hline Medline & 29/07/2019 & 485 \\
\hline Psych Info & 29/07/2019 & 19 \\
\hline $\begin{array}{l}\text { Embase classic + } \\
\text { Embase }\end{array}$ & 29/07/2019 & 359 \\
\hline Emcare & 29/07/2019 & 94 \\
\hline $\begin{array}{l}\text { MEDLINE Epub ahead } \\
\text { of print and in-process } \\
\text { and other non-indexed } \\
\text { citations }\end{array}$ & 29/07/2019 & 26 \\
\hline CINAHL & 29/07/2019 & 83 \\
\hline Total & & 1066 \\
\hline
\end{tabular}

randomised controlled trials (RCTs) to case studies, with no single method being able to answer all relevant questions about the effectiveness of all public health interventions. ${ }^{21}$ This study drew on a realist approach to evaluate complex interventions. ${ }^{22}{ }^{23}$ We used an approach to data synthesis which focused on understanding the mechanisms by which an intervention works or not, ${ }^{24}$ the context in which interventions are implemented and the different levels at which they operate.

\section{Data sources}

We searched Medline, Medline Epub ahead of print and in-process and other non-indexed citations, PsychINFO, EMBASE Classic+EMBASE, EMCARE and CINAHL from the period of 1 January 2000 to 29 July 2019. The databases searched and results are presented in table 1 . We used search terms (table 2) for each database to guide our search. We supplemented our search of the peer-reviewed literature with a grey literature search. We searched topicspecific organisations online portals including the CDC Community Guide, American Public Health Association, Commonwealth Fund, Robertwood Johnson Foundation, WHO Europe, WHO USA, National Institute of Health and Care Excellence, UK, Cochrane and Campbell, NZ Ministry of Health and Aboriginal Health Info Net.

The inclusion criteria for the study are listed in box 1 . Included studies needed to evaluate a preventive intervention that mobilised CHWs/lay health workers and was delivered in any PHC setting with disadvantaged population groups. Studies that were based in hospitals were excluded. The intervention population included adults with or without chronic health conditions. Disadvantaged population characteristics were identified based on geographical remoteness and access to PHC, socioeconomic condition, cultural and linguistic background, and Indigenous heritage.

The healthcare interventions are quite different in different health systems. We focused in countries with developed health systems where the CHW role supplements rather than replaces traditional roles of doctors, nurses and other health professionals. Therefore, we selected studies that were conducted in Organisation 
Table 2 Basic search strategy used for the review

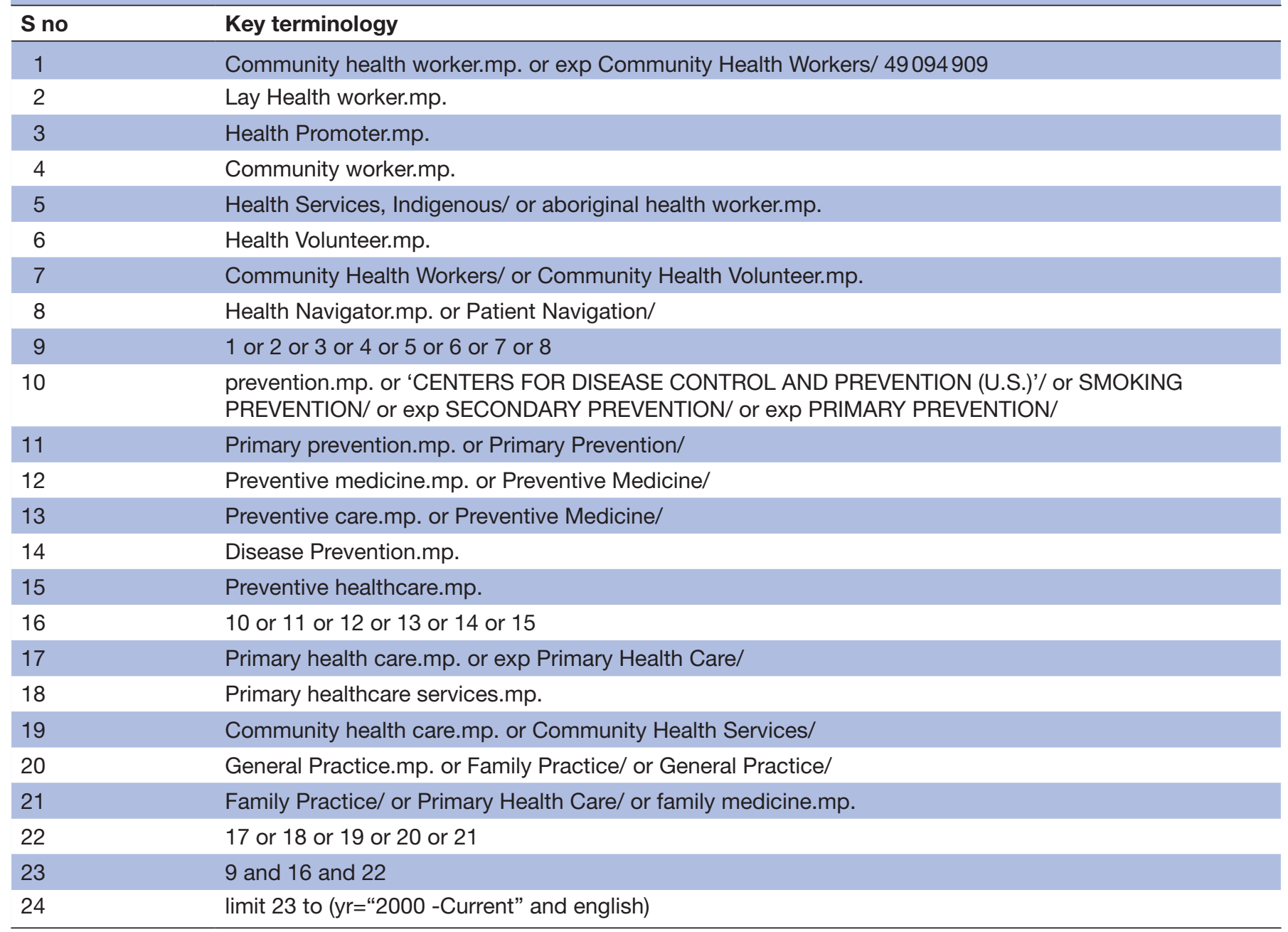

for Economic Cooperation and Development (OECD) countries.

\section{Study assessment process}

Initial titles and abstracts were screened by NS and SKM to determine the eligibility of the studies. The remaining studies required full text review, which was conducted equally by $\mathrm{MH}, \mathrm{EH}$ and JL. The final inclusion was

\section{Box 1 Inclusion criteria for studies}

1. Community health workers.

2. Years: 2000 to current (29 July 2019).

3. English language.

4. OECD countries.

5. Related to intervention/ control/ comparison.

6. Primary healthcare setting.

7. Excluded hospital settings.

8. Exclusion based on CALD communities and disadvantaged population was carried out at the later stage of review process.

CALD, culturally and linguistically diverse; $\mathrm{OECD}$, Organisation for Economic Cooperation and Development. determined through joint discussions and review among the authors.

\section{Data extraction}

Data extraction was conducted using excel spreadsheet under predefined variables: citation, context (country, service), study setting, focus of the study, study design, type of participants, sampling, sample characteristics, response rate/drop outs, control or comparison group, number of participants, type of CHW/role, CHW characteristics (age, sex, ethnicity, condition), CHW recruitment and training, intervention type, intervention duration/ frequency/mode of conduct, evaluation (impacts on health services, quality of care, patient behaviours, risk factors, patient health service use, screening, disease incidence, mortality, quality of life), economic evaluation, barriers and enablers mechanism, authorising environment.

\section{Participants}

This study focused on socioeconomically disadvantaged population groups. Thus, the study population included: those with limited access to material and social resources 
because of social and economic factors; CALD population (with diverse language, ethnic background, nationality, dress, tradition, food, societal structures, art and religious characteristics) ${ }^{25}$; people in rural settings, whose ability to access PHC is limited by their rural or remote geographical location; and Indigenous or Aboriginal people.

\section{Quality appraisal}

We assessed the quality of included systematic reviews using A Measurement Tool to Assess Systematic Review (AMSTAR). AMSTAR is comprehensive quality appraisal instrument that enables detailed assessment of systematic reviews process that include randomised or nonrandomised studies of healthcare interventions or both. ${ }^{26}$ For the quality assessment of our included studies, we used the effective public health practice project quality assessment tool in order to assess the methodological quality and the relevance of the study. ${ }^{27}$ Studies were evaluated across eight categories (selection bias, study design, confounders, blinding, data collection methods, withdrawals and drops, intervention integrity, analyses) with each given a score of 1 to 3 (1=strong, 2=moderate and $3=$ weak).

\section{Analysis}

The analysis was guided by the research question which focused on understanding models of CHWs involvement in preventive care. Because of the heterogeneity of the included studies in terms of their research design, metaanalysis was impeded. We conducted descriptive analysis of studies, interventions, roles and training of CHWs. The analysis of impacts and outcomes was conducted taking into consideration the intervention type and the quality of studies. The information on barriers and enablers was extracted from the Discussion section of the original articles. The barriers and enablers were qualitatively analysed considering the intervention type and the quality of studies.

\section{RESULTS}

A total of 1066 articles were identified during the initial search. After excluding 283 duplicates, 783 articles were screened, and a further 673 articles were excluded after title and abstract screening. Due to the diverse role of CHWs, it was difficult to assess the eligibility of articles from title and abstract search, 110 underwent an initial full text review, resulting in 53 exclusions. We excluded 20 more articles at the time of extraction because they were not focused on primary or secondary prevention, did not evaluate an intervention, were hospital based, were a systematic review not focused on CHWs, or were not in OECD countries. Thirty-seven articles were included and underwent data extraction (figure 1). The characteristics of the included studies are summarised in tables 3 and 4 . Of the total 37 studies whose quality were assessed, 16 studies were categorised as moderate and 21 studies were categorised as weak (see table 5 and online supplementary file 1). Articles were not excluded due to a low-quality rating but the quality appraisal was considered for analysing effectiveness.

\section{Study designs}

Studies were selected irrespective of their study design. Of the total 37 included studies, 18 were RCTs, ${ }^{28-45}$ four had one group pre-test post-test design, ${ }^{46-49} 13$ were nonrandomised trials $^{33}{ }^{50-61}$ and two studies were qualitative. $^{4062}$

\section{Country}

The majority of the studies were carried out in the USA. One study in Mexico, one in the US and Mexico, one in Belgium and one in New Zealand.

\section{Study settings}

All the studies were executed in PHC and community settings. PHC settings included primary health clinics, community health centres, medical centres and cancer screening centres. Participants were recruited from various community settings such as community organisations, community resource centres, senior centres, social service centres and rural community centres.

\section{Types of participants}

Consistent with our selection criteria, all the studies were carried out among disadvantaged population groups. Studies conducted in the USA were among Hispanic or Latinos, African-American and Native American communities. The study from New Zealand was conducted among the Maori community members whereas in Belgium the study was conducted among older women living in semi-rural parts of the country. The study population were marginalised in societies that lead to disparities in their health and their healthcare access. The study populations' disadvantaged status was based on: ethnic status, minority status, migration status, low income, poor healthcare access, lack of health insurance and high prevalence of disease on the population.

\section{Types of diseases}

Preventive interventions focused on both chronic and nonchronic conditions. Seventeen studies sought to enhance preventive care for three different types of cancer. Of those 17,8 were on colorectal cancer, ${ }^{30} 31343637576163$ 2 were on cervical cancer ${ }^{56} 59$ and 4 were on breast cancer..$^{32} 334145$ In the remaining three studies, cancer prevention was the focus in all three. ${ }^{404254}$ There were seven studies on diabetes prevention, ${ }^{35} 394349525859$ and five on cardiovascular disease prevention. ${ }^{29}$ 46-48 62 Three focused on managing hypertension, ${ }^{28}$ depression ${ }^{38}$ and smoking. ${ }^{44}$ Others were aimed at reducing infant mortality, screening for lead poisoning, ${ }^{53}$ preventing sexually transmitted diseases (STDs) ${ }^{64}$ and human papillomavirus ${ }^{55}$ infection. There was only one study that carried out an intervention to prevent multimorbid conditions. ${ }^{51}$ 


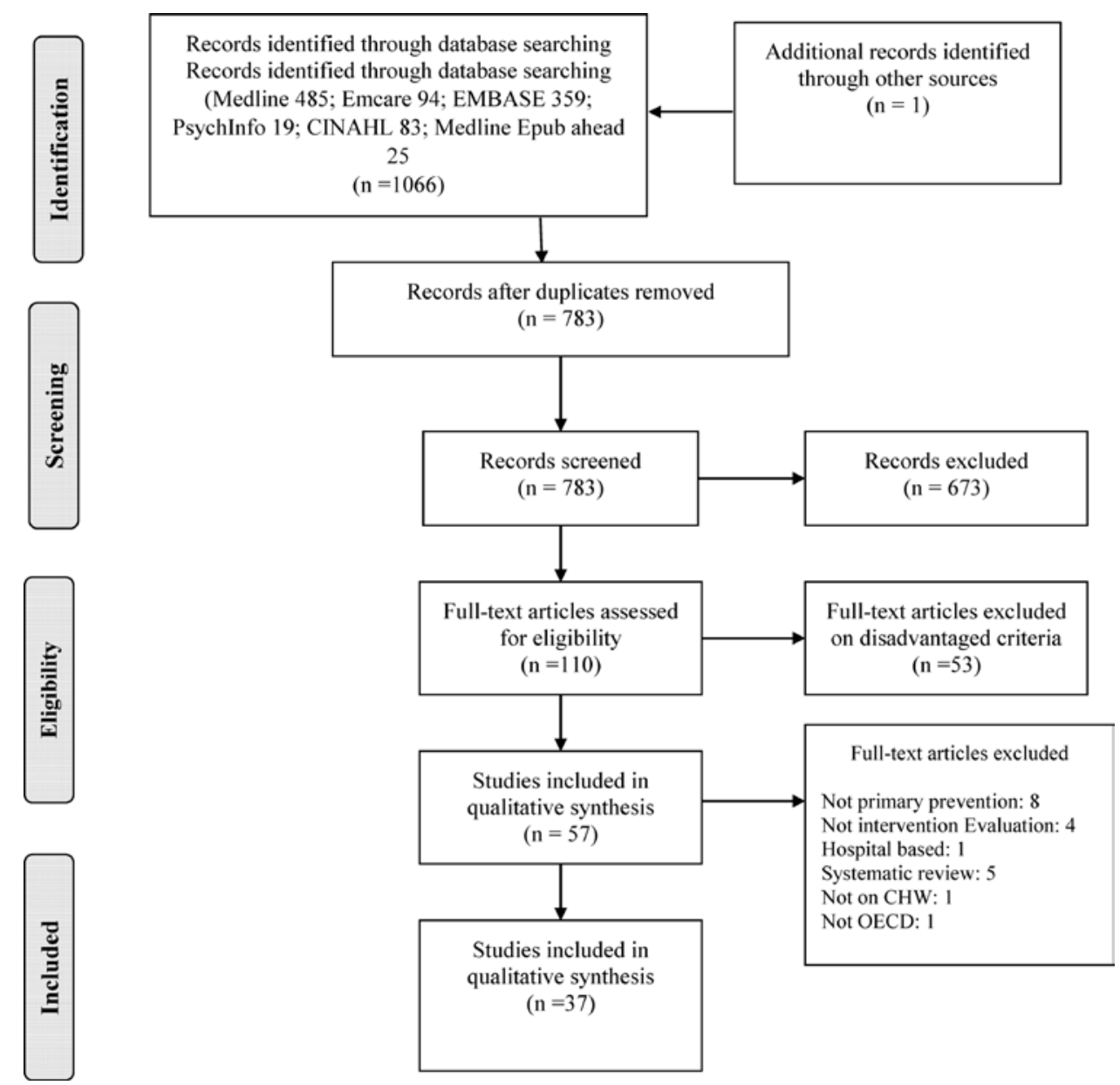

Figure 1 PRISMA flowchart. PRISMA, Preferred Reporting Items for Systematic Reviews and Meta-Analyses.

\section{Types of interventions and roles of CHWs}

The interventions durations varied, lasting from 90 mins to 2 years. Four different types of interventions were identified based on the strategies used to deploy CHWs for the preventive measures (see online supplementary file 2). They were:

1. Education interventions. ${ }^{28} 2938-4046474953556062$

2. Navigation interventions. 303233353742456163

3. Education + navigation interventions. 31343641545657

4. Education + self-management interventions. ${ }^{43444850-52585964}$

Education interventions were based on the principle of preventing disease through education and awareness of social and clinical risk factors enabling positive change in health behaviour. Education session were provided to participants either in group or in person or in combination of group session and individual coaching. The education materials used were either curriculums that were developed as a part an intervention itself or used from an already developed educational module. The education materials were often culturally tailored, translated and delivered in participant's community language.

The navigation interventions focused on reducing barriers to healthcare access. Eight out of nine studies that used navigation interventions in this review were carried out to identify and reduce barrier to cancer screening among participating communities.

Education plus navigation interventions were more holistic in their approach compared with interventions that focused on either strategy alone. Where both were provided, along with education, the participants were assisted to identify and overcome barriers to healthcare access. This type of intervention was carried out predominantly for cancer prevention.

Education plus behavioural or self-management interventions were the second most frequently reported interventions after the education interventions. Apart from providing education on disease risk factors, this type of interventions focused on enabling participants to choose healthy lifestyle options and change their behaviour accordingly. The CHWs provided emotional as well as practical support along with education to enable behaviour change among study participants through selfmanagement techniques.

\section{Types of CHWs}

CHWs were described using a range of terms such as: promotores de salud/ promotora, ${ }^{28} 29394046-495152555859$ health advocate/lay helper, ${ }^{29}$ patient navigator/ health navigator/navigator/ peer-patient navigator/health 


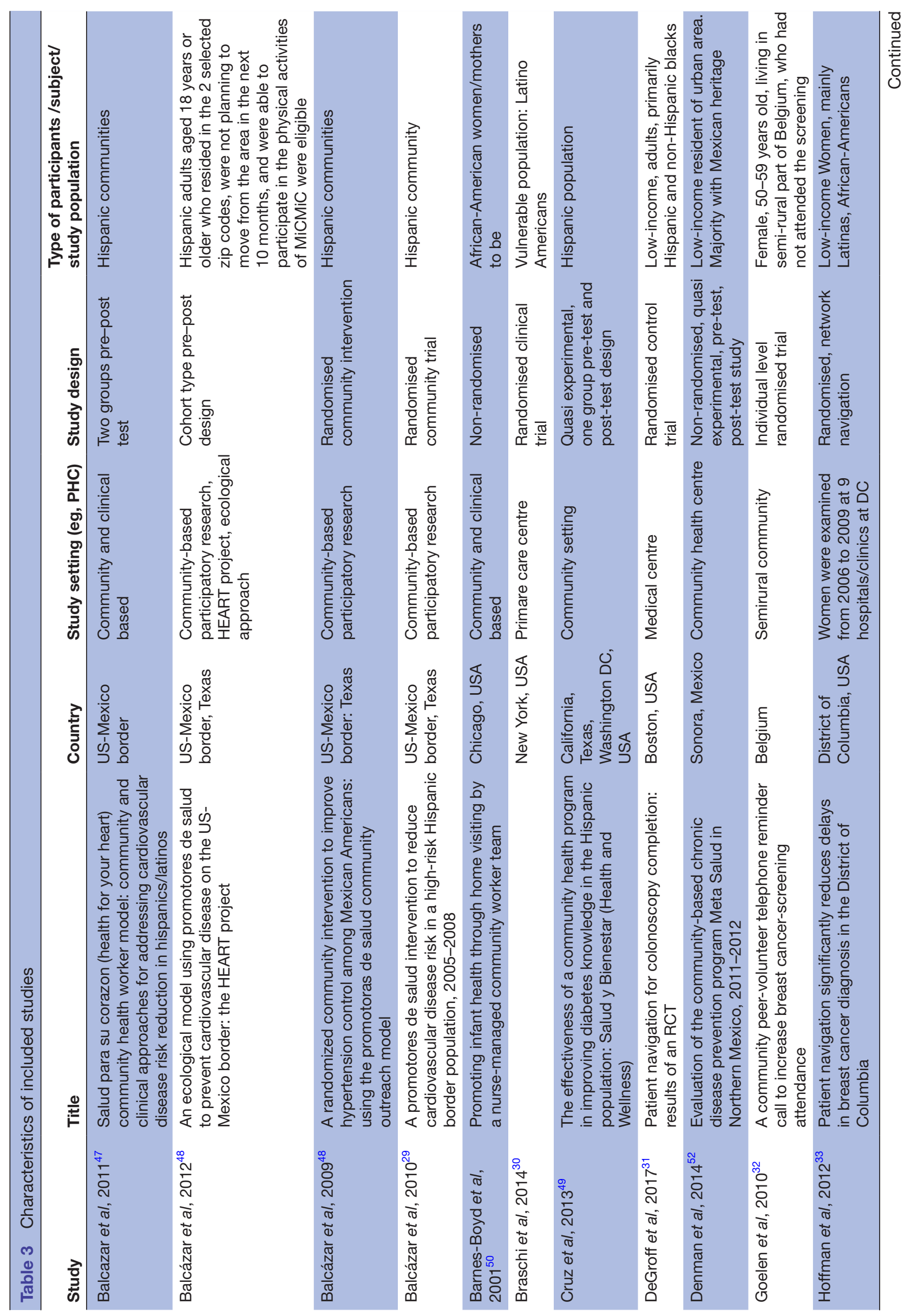

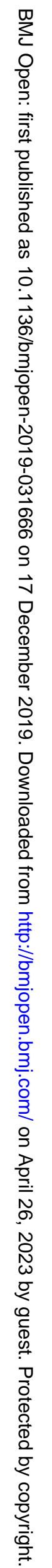




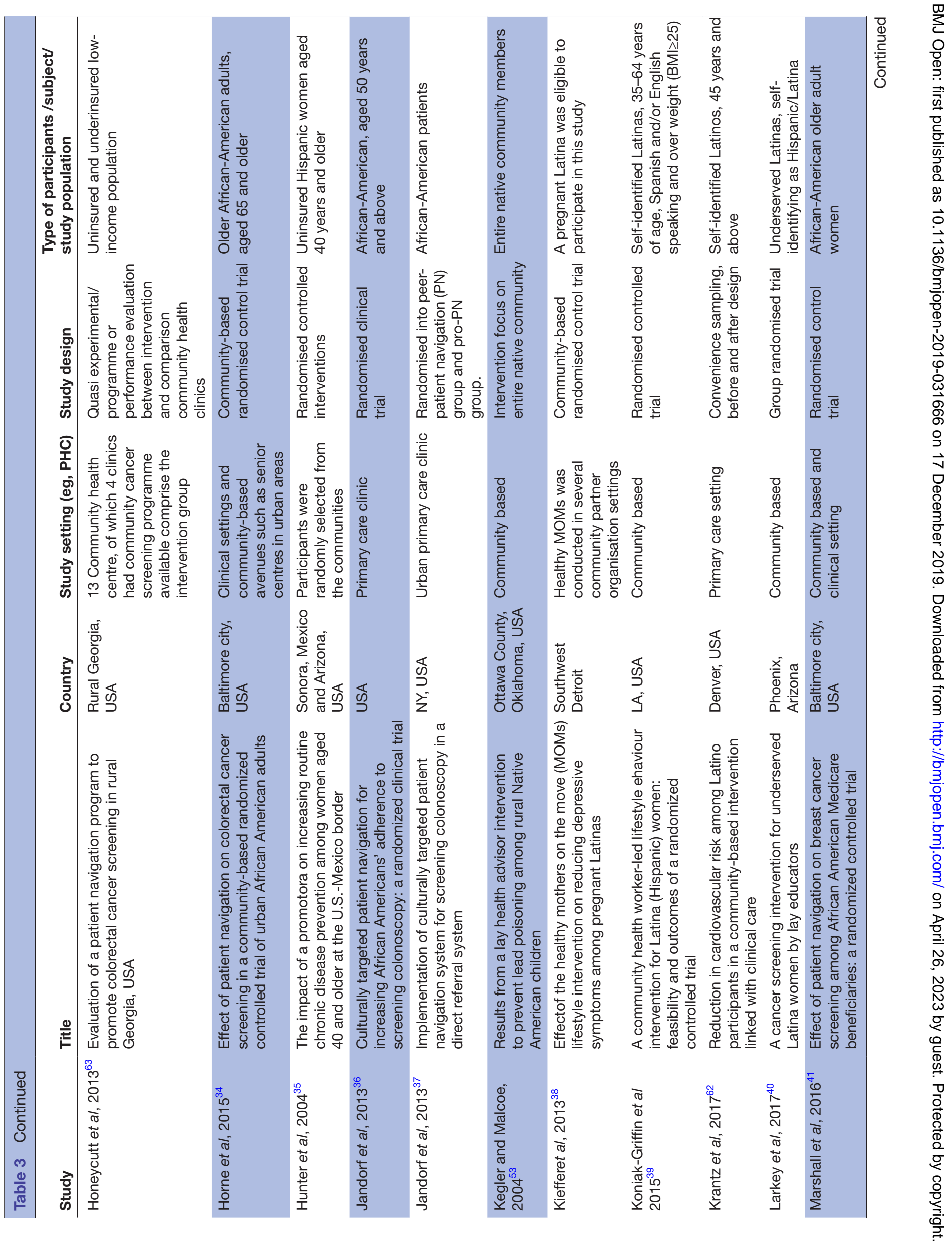




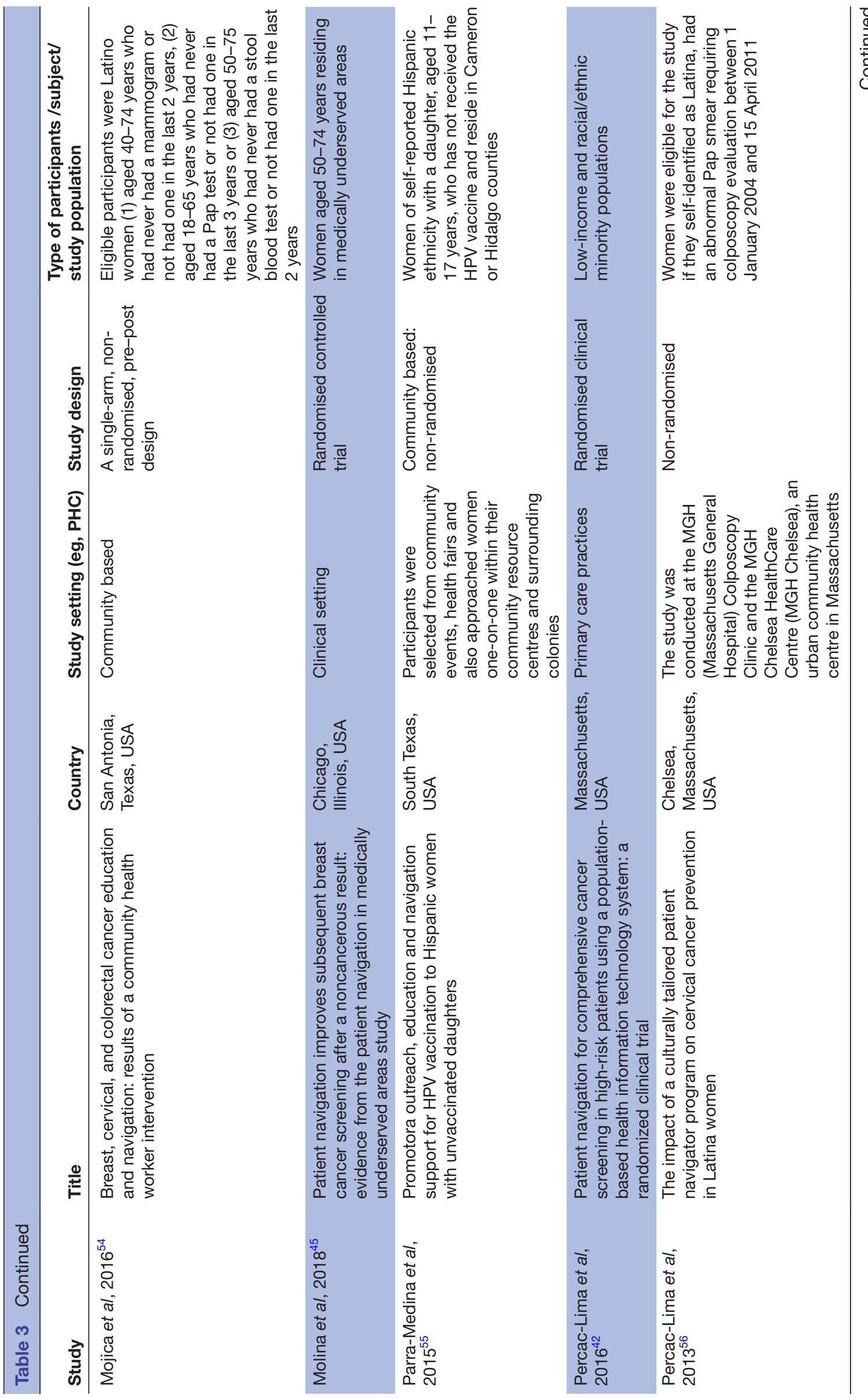




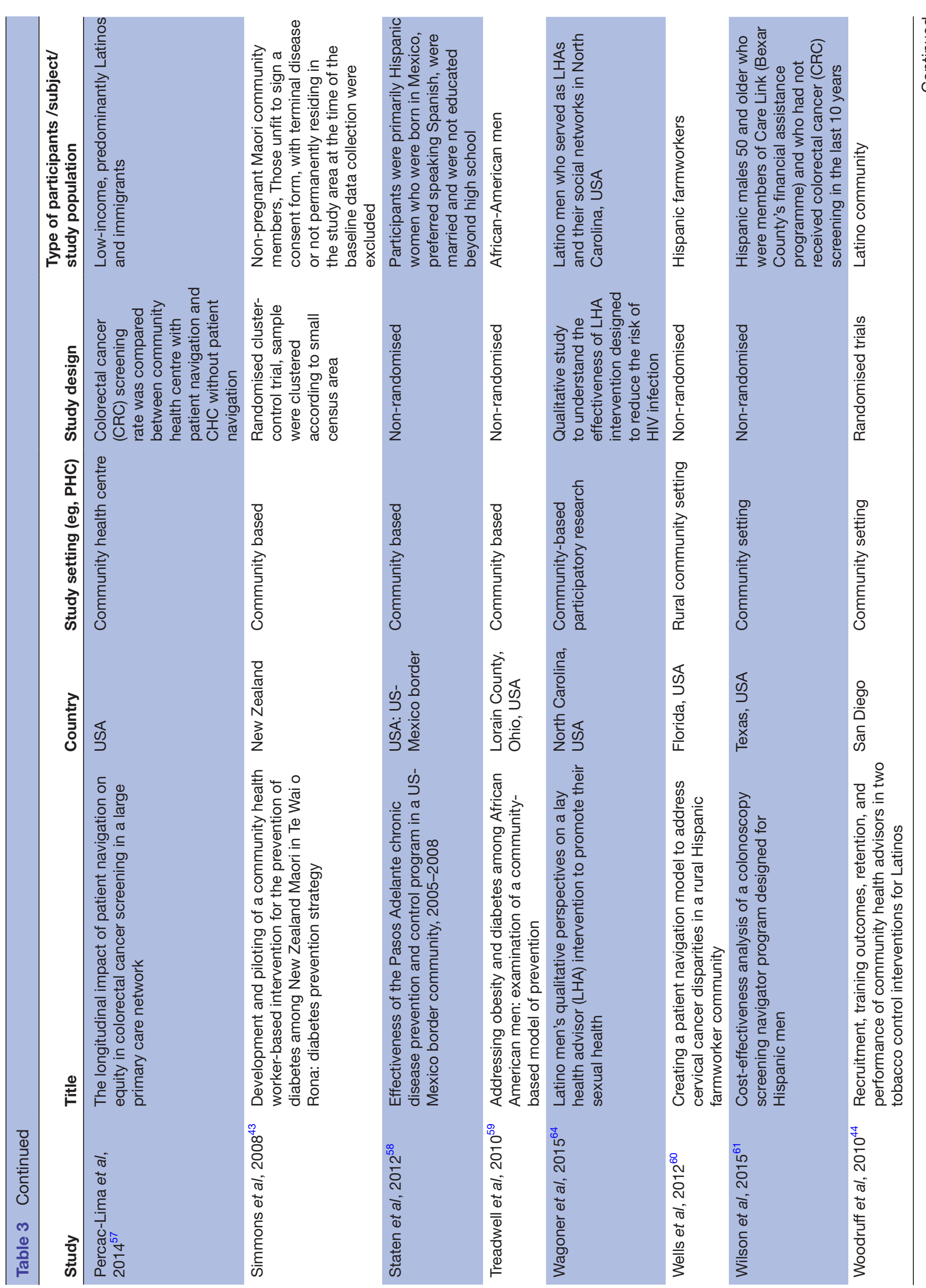


coordinator, 303334363741424556576063 lay health advisor/ lay navigator/lay health assistant, ${ }^{315364}$ peer volunteer, ${ }^{32}$ women health advocates, ${ }^{38} \mathrm{CHWs}^{35} 43546162$ and community health advisor. ${ }^{44}$

CHWs were mostly females (only in few instances CHWs were male) and were members of the communities they served. They were bilingual individuals who spoke English together with their community language. They had previous experience working in community sectors or as CHWs.

Thirty-two out of 37 included studies provided some form of training to CHWs before deploying them in preventive interventions. Training was provided to help the CHWs to gain competencies in activities that were directly related to their roles. Thus, the training provided to CHW differed from programme to programme. CHWs training programmes were variable in content and duration of the trainings. The duration of trainings varied lasting from 4 hours to courses that lasted for 6 months. For education-related interventions, CHW's training was structured around curriculums or educational modules that were being delivered as a part of interventions. For navigation-related interventions, training were structured around operational or implementation aspects. CHWs training identified in the review included, but were not limited to the following topics:

1. Your heart, your life curriculum. ${ }^{28} 294647$

2. Basic skills of reducing and preventing cardiovascular disease (CVD) in Hispanic communities. Training on capacity-building strategies, tools for identifying community resources, advocacy, food handling techniques, preintervention postintervention data collection techniques. ${ }^{48}$

3. Didactic training on general health advocacy, maternity-child health issues, field experience with health aids in local health departments. ${ }^{50}$

4. Training on chronic disease management and on application of the 'Transformation of health conceptual framework' to facilitate behaviour change among participants. $^{51}$

5. Review of diabetes disease, how to use study questionnaire and study materials on diabetes education, nutrition and physical exercise, role of health promoters for community health promotion. ${ }^{49}$

6. Training on motivational interviewing. ${ }^{31}$

7. Cancer screening techniques, study design and operational aspects such as handling telephone reminder call system and study registration. ${ }^{32} 37$

The training sessions were administered through a wide variety of individuals and institutions. Some training was administered by a lead programme coordinator or programme staff. Other training was provided by a lead CHWs who had previous experience delivering same or similar types of interventions to the community. On some occasions, CHWs were provided with training by healthcare providers. Some of the programmes required CHWs to obtain CHW certification from registered educational institutions. 


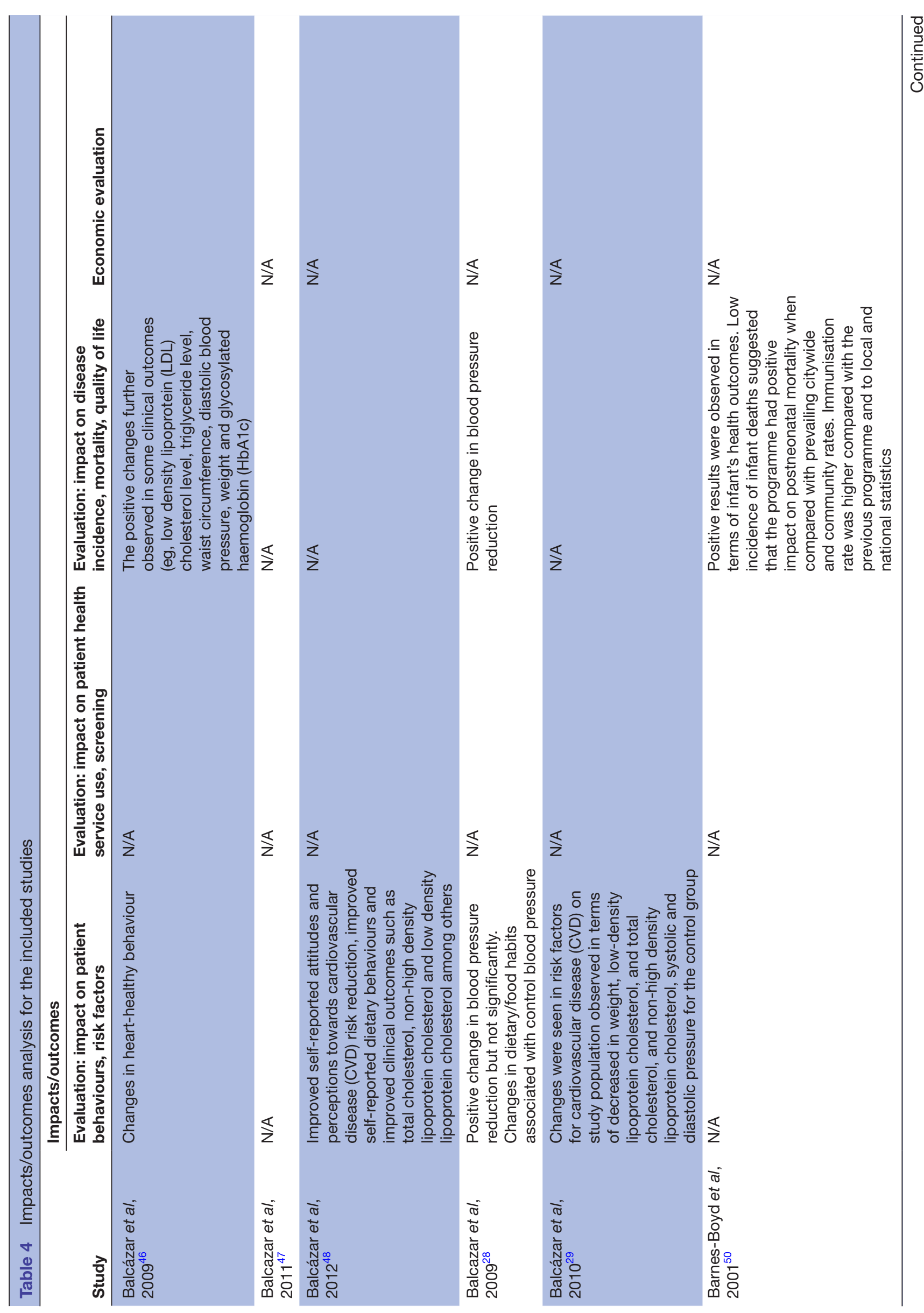



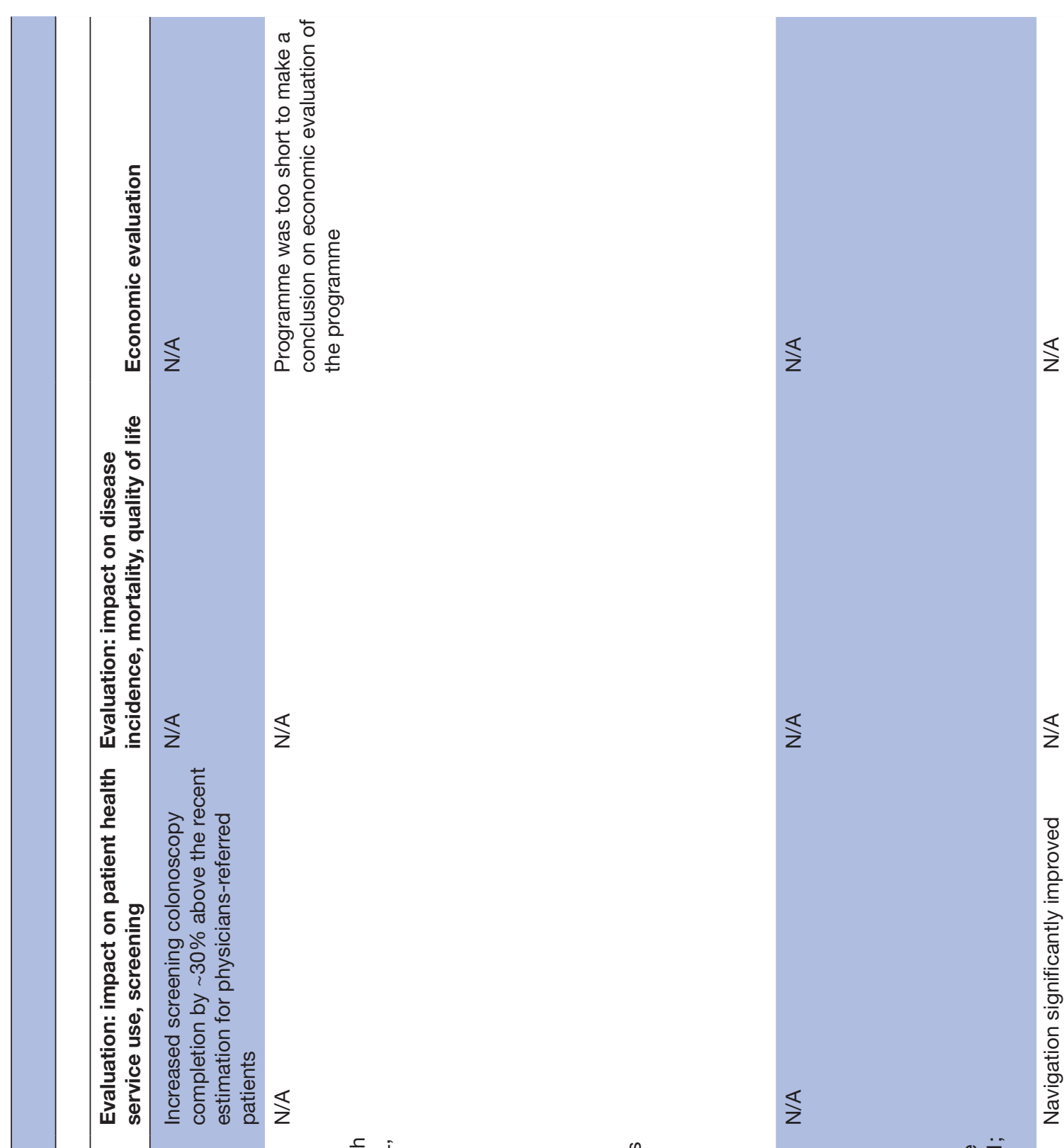

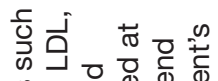

$\overleftarrow{s}$

$\$$

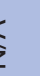

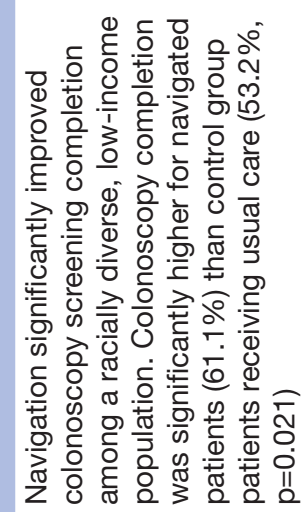

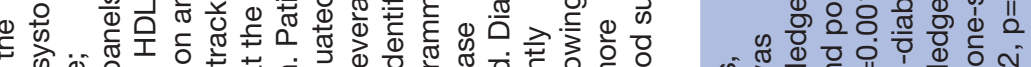

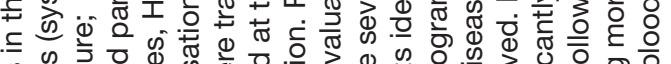

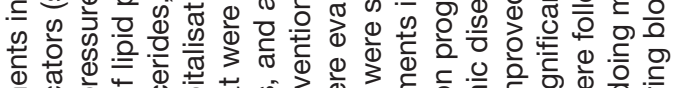

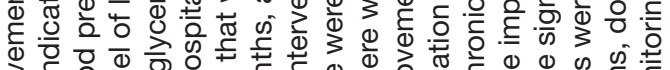

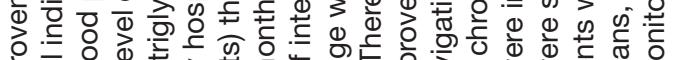

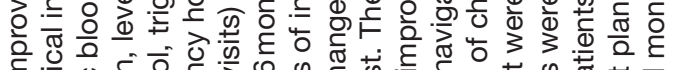

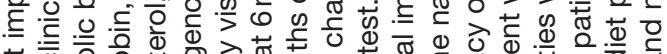

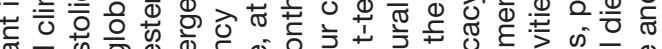
\%

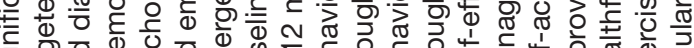

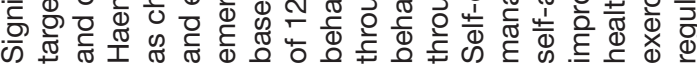

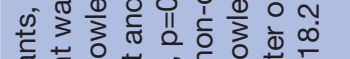

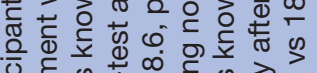

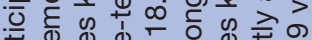

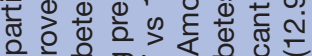

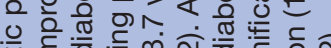

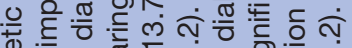

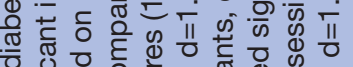

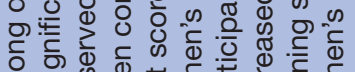

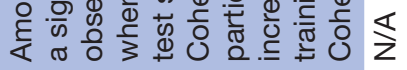

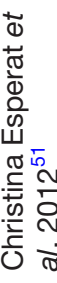

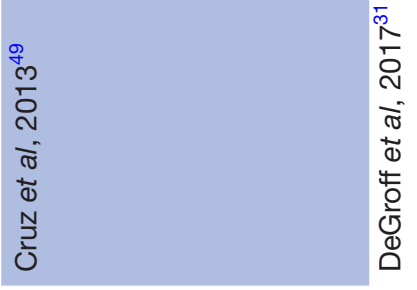




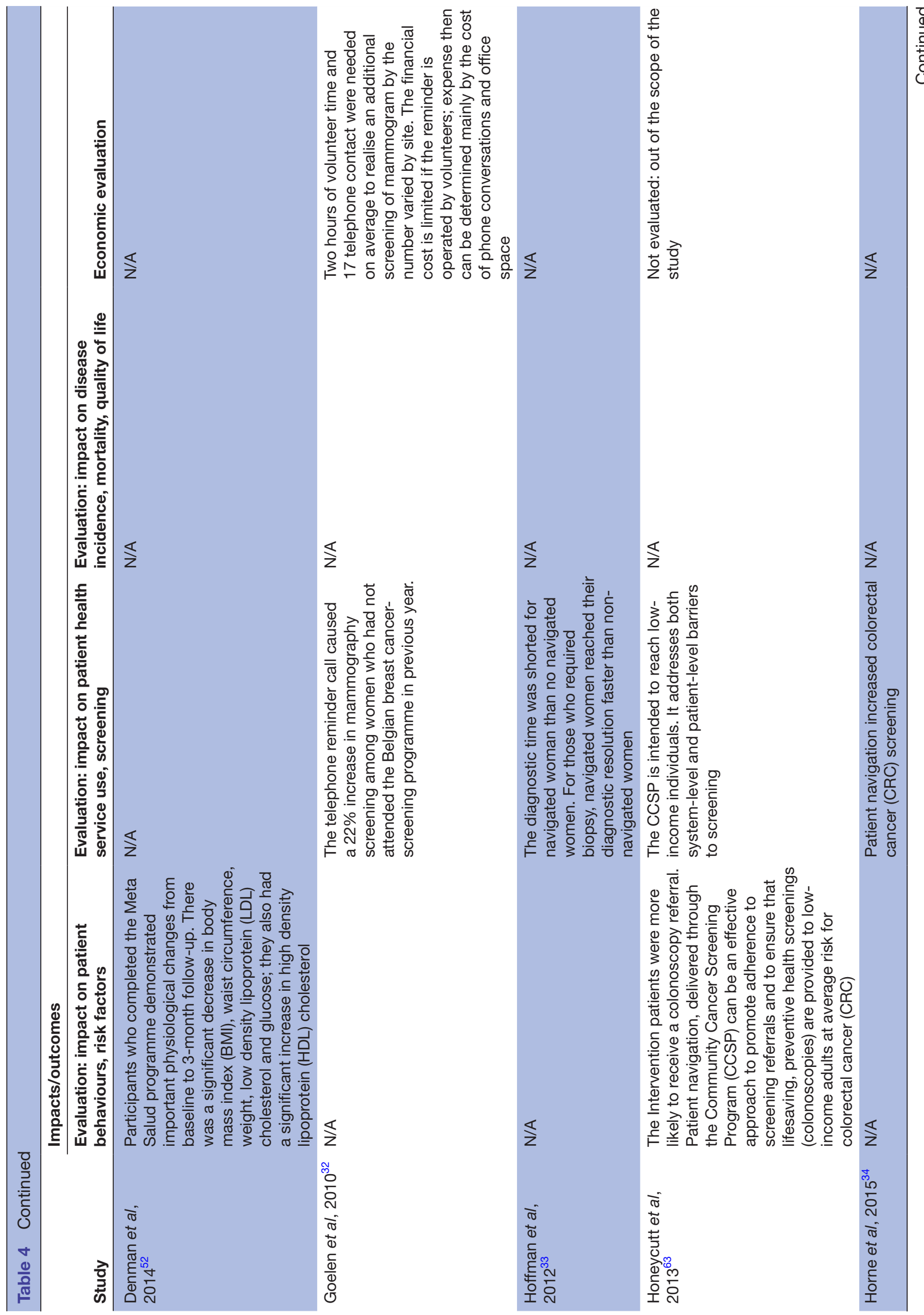




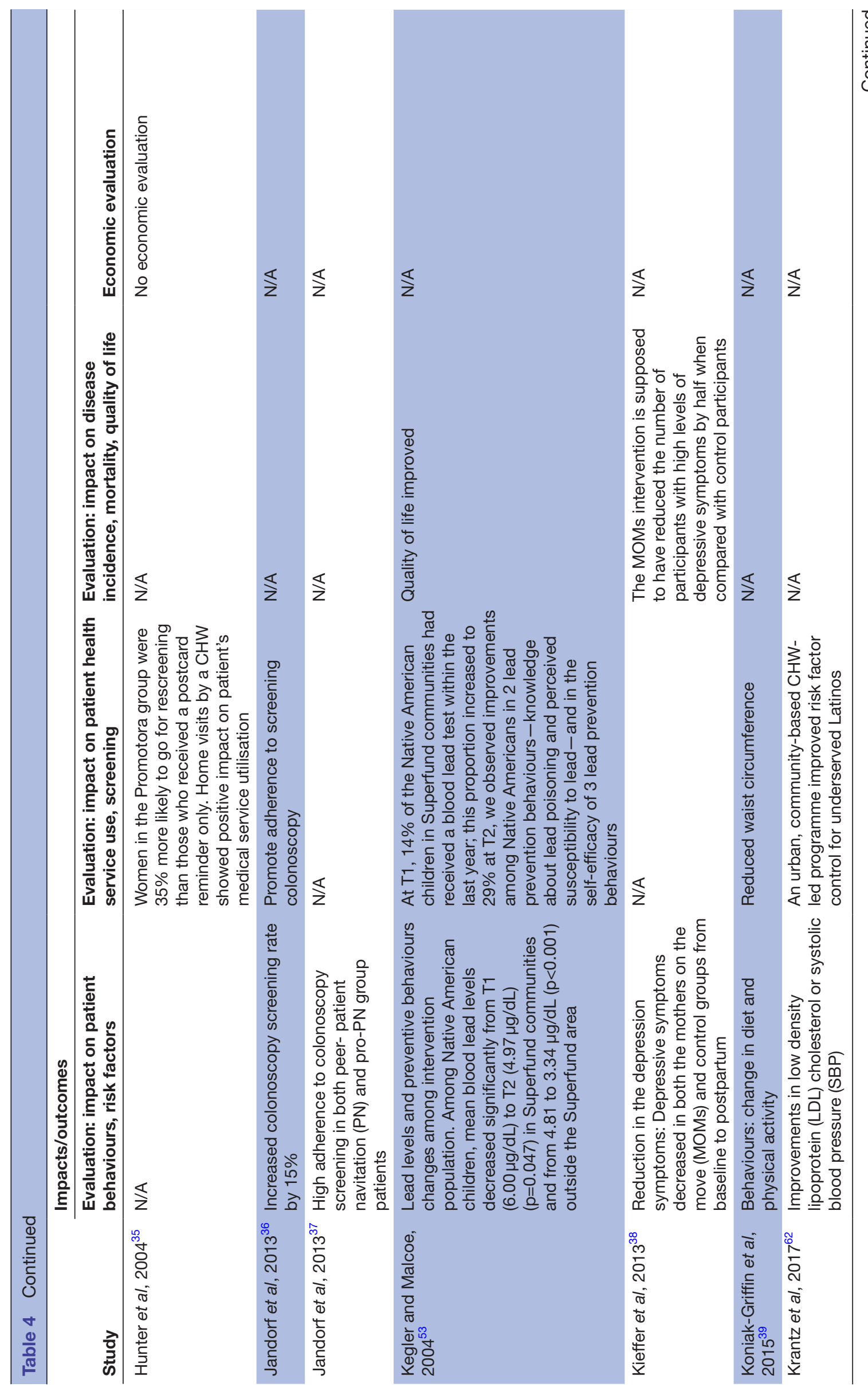




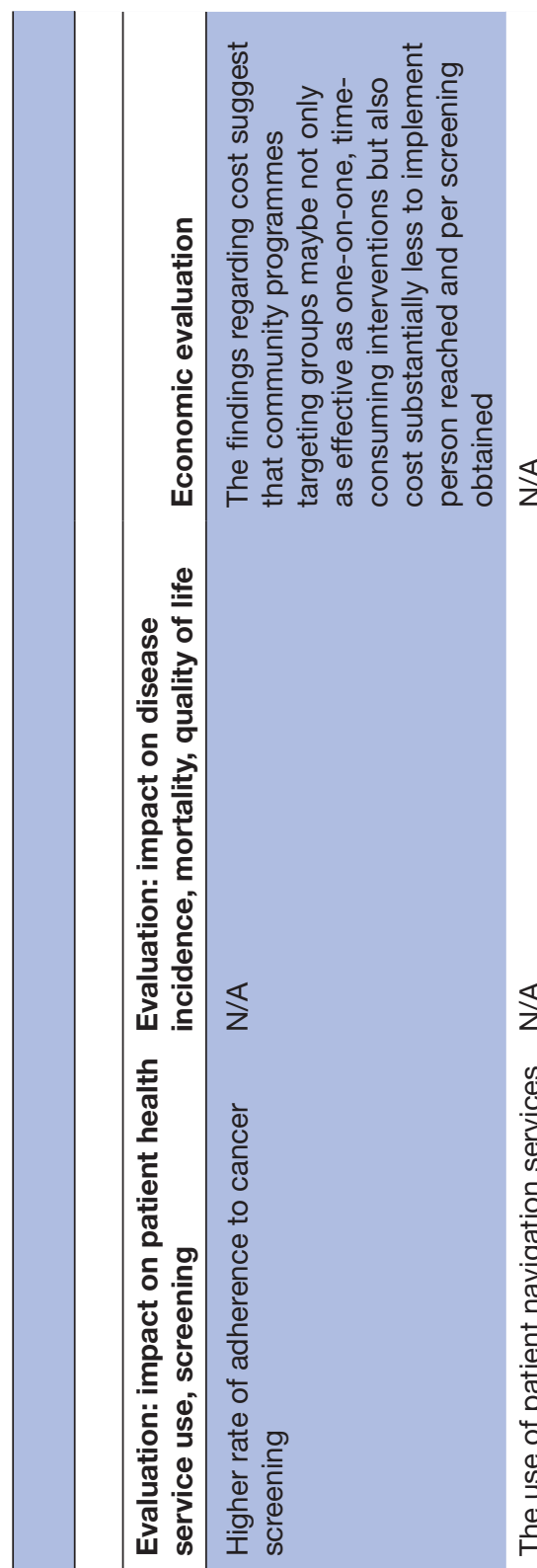

$\$$

乌

等

ᄃ

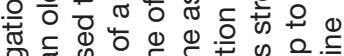

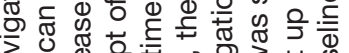

ฮ

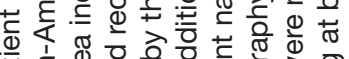

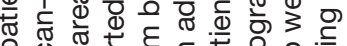

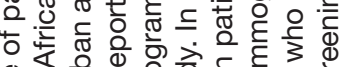

Ф

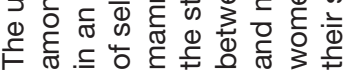

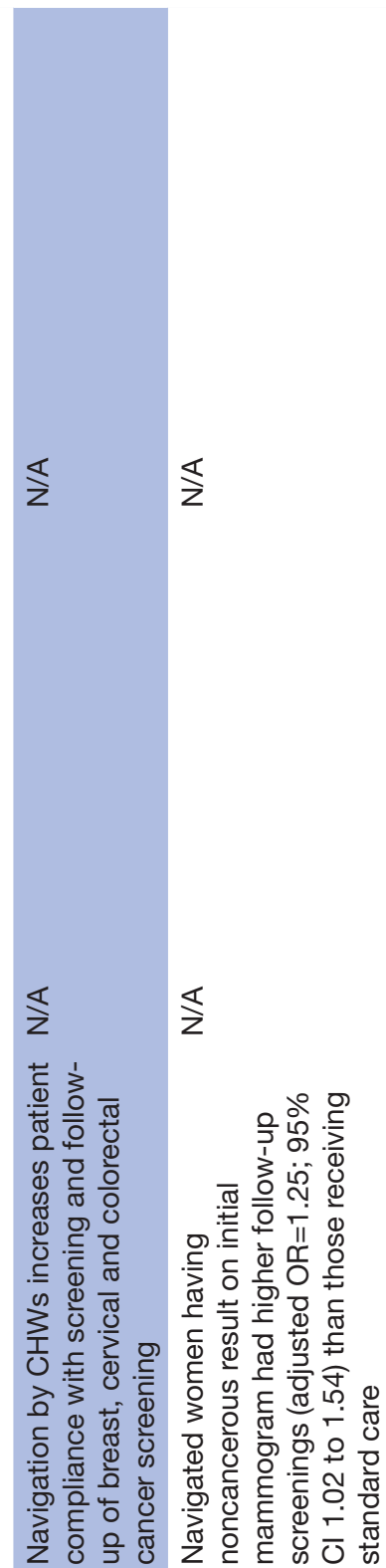

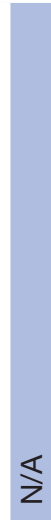
일.

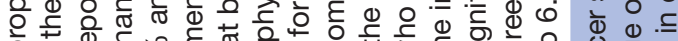

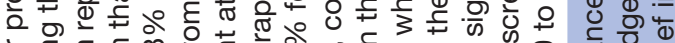
迹.

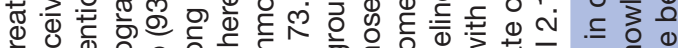
万人

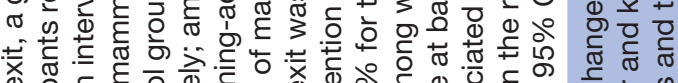
ช

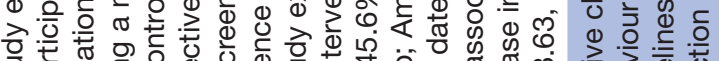

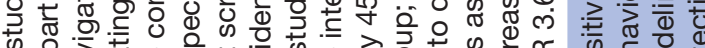

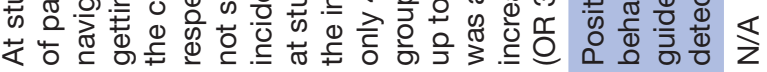
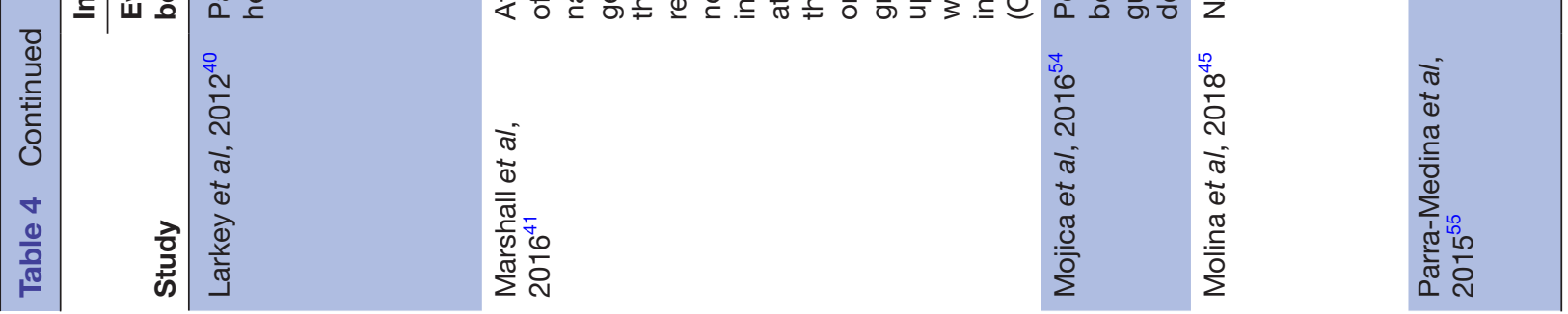


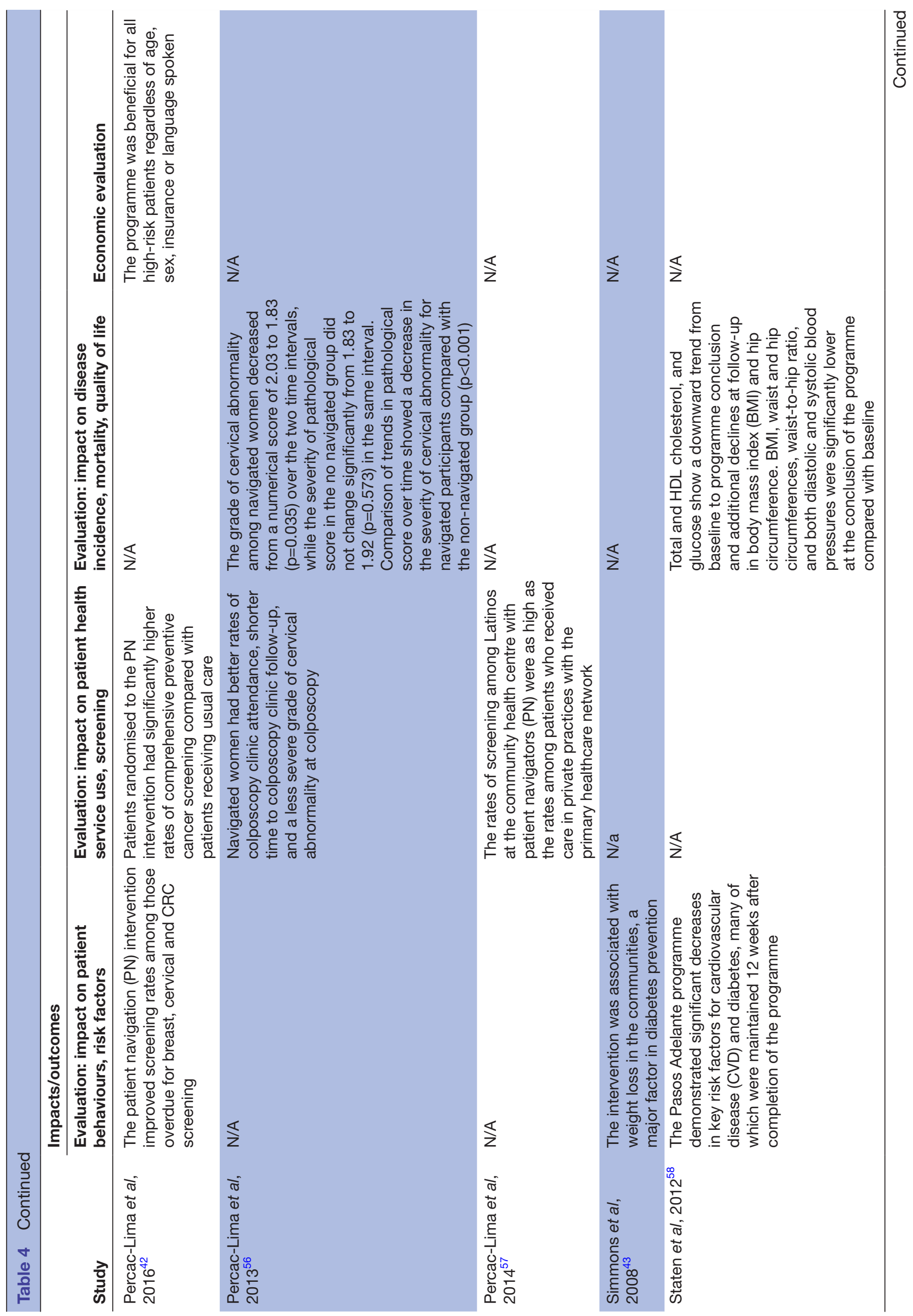




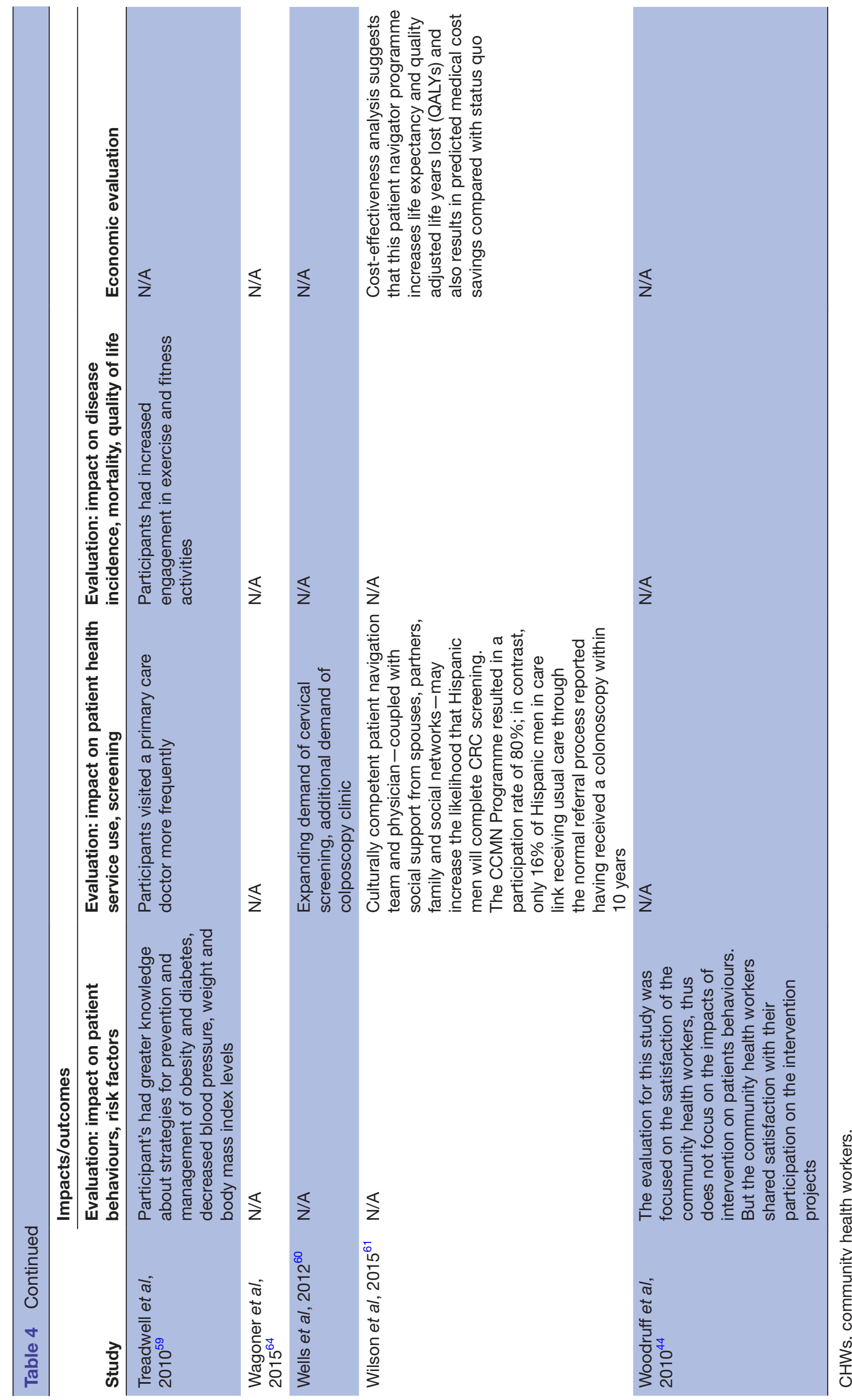


Table 5 Interventions versus outcomes analysis

\section{Outcomes}

\begin{tabular}{|c|c|c|c|c|c|}
\hline Intervention types & $\begin{array}{l}\text { Impact not } \\
\text { measured }\end{array}$ & $\begin{array}{l}\text { Impact on patient } \\
\text { behaviours, risk } \\
\text { factors }\end{array}$ & $\begin{array}{l}\text { Impact on patient } \\
\text { health service use, } \\
\text { screening }\end{array}$ & $\begin{array}{l}\text { Impact on } \\
\text { disease } \\
\text { incidence, } \\
\text { mortality, quality } \\
\text { of life }\end{array}$ & $\begin{array}{l}\text { Economic } \\
\text { impact }\end{array}$ \\
\hline Education only (E) & 1 & 9 & 2 & - & - \\
\hline Navigation only (N) & - & - & 9 & - & 1 \\
\hline $\begin{array}{l}\text { Education and } \\
\text { behavioural or self- } \\
\text { management (E+SM) }\end{array}$ & 2 & 6 & - & 1 & - \\
\hline Quality of study & Weak $=3$ & $\begin{array}{l}\text { Moderate }=6 \\
(5=E ; 1=E+S M) \\
\text { Weak=9 } \\
(4=E ; 5=E+S M)\end{array}$ & $\begin{array}{l}\text { Moderate }=10 \\
(6=N ; 4=E+N) \\
\text { Weak=8 } \\
(2=E ; 3=N ; 3=E+N)\end{array}$ & Weak $=2$ & Weak $=1$ \\
\hline
\end{tabular}

The numbers within the table represents the number of included articles.

\section{Types of CHWs role}

This review identified four categories of role (ie, education, navigation, support and research) played by the CHWs in preventive care (see table 6).

Under each role, the CHWs took various responsibilities which included some clinical functions such as, under supervision, CHWs provided instructions on holistic clinical approach: infant care, hygiene, skin care, nutrition and accident prevention. It is interesting to note that none of the studies commented on how these CHW's roles were perceived or responded by other healthcare professionals.

\section{Impacts/outcomes}

The review extracted interventions and their impacts under five different categories:

1. Health services, quality of care.

2. Patient behaviours, risk factors.

3. Patient health service use, screening.

4. Disease incidence, mortality, quality of life.

5. Health economics.

Impacts of the interventions were most frequently evaluated using quantitative measures. Only one study used a qualitative evaluation of the programme to assess the satisfaction of CHW with their participation in the

Table 6 Role of CHWs

\begin{tabular}{ll}
\hline Type of role & Responsibility \\
\hline 1. Educational role & Facilitate the delivery of culturally appropriate interventions in community language. \\
& Under supervision, CHWs provided instructions on holistic clinical approach: infant care, hygiene, \\
2. Navigational role & Help patients negotiate with the health system to reduce barriers to screening. \\
& Follow-up with participants in person or over the phone. \\
& Promote awareness of the preventive interventions available to the population. \\
& Supsist patients with transportation. \\
& Provide access to resources, such as food. \\
& Cenduct home visits or do telephone follow-ups. \\
& Help patients set weekly goals and record whether those goals were achieved periodically. \\
3. Support role & Provide informal counselling and motivational talks to participants. \\
& Participate in physical activity with community members such as walking. \\
4. Research role & Recruitment of participants. \\
& Conduct interviews and collect quantitative data. \\
& Assessment of behaviour change.
\end{tabular}

CHWs, community health workers. 
project. ${ }^{44}$ Only 1 out of 37 included studies evaluated costeffectiveness of a navigation programme to colonoscopy among Hispanic men. ${ }^{61}$ This study suggested that the patient navigation programme resulted in medical cost saving compared with existing practice as the programme was successful in screening at least $18 \%$ of the person contacted by the navigator. The results showed that on average, participants prolonged their life expectancy by 6 months and gained 0.31 additional quality adjusted life years lost (QALYs) compared with not participating in the programme. The study identified an estimated US $\$ 1148$ cost saving per participant resulting from participating in the navigator programme compared with controls. ${ }^{61}$

The impact on disease incidence, mortality or quality of life was reported only by two studies. One study demonstrated improved infant's health outcomes. ${ }^{50}$ The low incidence of infant deaths suggested that the CHW programme had positive impact on postnatal mortality when compared with prevailing citywide and community rates. Immunisation rates were higher among participants compared with the previous programme and to local and national statistics. The other study identified the positive impact of a culturally tailored patient navigation programme on cervical health outcomes. ${ }^{56}$ The study identified that the grade of cervical abnormality among navigated women decreased from a numerical score of 2.03 to 1.83 ( $\mathrm{p}=0.035$ ) over the two time intervals, while the severity of pathological score in the nonnavigated group did not change significantly from 1.83 to $1.92(\mathrm{p}=0.573)$ over the same period $(\mathrm{p}<0.001) .{ }^{56}$

Thirty-three studies reported positive impacts of CHW interventions on clinical disease risk indicators, screening rates and healthy behaviours. Clinical measurement of indicators such as low density lipoprotein (LDL) cholesterol level, triglyceride level, waist circumference, diastolic blood pressure, weight and glycosylated haemoglobin (HbA1c) $282938394346484951-5355585962$ were recorded and analysed from study populations before and after interventions and the results were evaluated based on the changes observed on the indicator measurements. The screening rates were calculated by observing the screening completion rate among the study population. ${ }^{30-3740-42545657606163}$

In analysing the interventions against outcomes, we identified that 9 out of 12 education only interventions and 6 out of 9 education and self-management interventions showed positive behavioural outcomes. All nine navigation only intervention showed positive health service outcome, whereas seven out of seven education and navigation intervention showed positive screening service use outcomes (see table 5).

Education focused interventions were most effective in changing patient behaviour. Of the 15 studies that identified positive patient behaviour outcomes, 9 were education only interventions and 6 were education and behavioural or self-management interventions. The analysis also revealed that navigation interventions were most effective in improving screening service use. Of the 17 studies that showed positive screening service use outcomes, 9 studies had navigation only intervention, 7 had education and navigation intervention and two had education only intervention.

Of the studies that investigated health service use outcomes, the majority were classified as moderate quality whereas the studies that investigated behavioural outcomes, the majority were classified as weak quality (see table 5).

\section{Enablers/barriers}

All the included studies demonstrated that CHWs had a positive impact on preventive care in PHC settings. Cultural and linguistic congruence between study populations and the navigators was one of the prominent enabling aspects contributing the interventions effectiveness. ${ }^{30} 3235363949515664$ The cultural similarities helped foster trust and build strong relationship between CHWs and study populations. Multiple contacts with the navigators also identified as an important enabling factor in seeking preventive care from the primary care more frequently. ${ }^{45}$ Not only were CHWs able to provide emotional and social support, ${ }^{39}$ the trusting and confidential relationship between CHWs and the study population enabled CHW to initiate discussion on health-related issues ranging from dietary issues to more sensitive issues such as condom use, cervical cancer screening, mammography screening, sexually transmitted disease (STD) and human immunodeficiency virus (HIV) screening.

Studies identified numerous barriers to the implementation of interventions. Short study duration was identified as barrier to the evaluation of long-term outcomes in some studies. ${ }^{31375163}$ The lack of generalisability of outcomes to other population groups was identified as a barrier to scaling up of intervention to other setting. ${ }^{31} 4142455657$ Some studies also reported difficulty encouraging participants to adhere to the intervention. ${ }^{34} 4041505455$ Often study participants were lost to follow-up mid-way through the project. In one study, a large proportion of women were lost to follow-up. ${ }^{41}$ The larger dropout rate in the group was attributed to contact fatigue among participants. In one study, CHWs reported that they encountered structural challenges making and having mothers keep vaccine appointments. ${ }^{55}$ Because vaccinations were only offered during business hours, mothers and children were required to take time off work and/or school. The out-of-pocket costs (copays, vaccine coverage) associated with the vaccination plans posed an additional barrier to receiving care.

Developing an effective CHWs intervention model was identified as a challenge that required change and development of new skills. It needed intensive initial training, regular continuing education, and ongoing team building for CHWs and other health professionals involved. In communities that were prone to community violence, ensuring the personal safety of the CHWs while in the field was identified as a challenge in one study. ${ }^{50}$ 


\section{Box 2 Roles of CHWs}

1. Cultural appropriate health information.

2. Navigation.

3. Coaching and social connect to resources but also social support.

4. Advocate for individual and community needs.

5. Provide individual and community capacity building — listening sessions, shared understanding, action team.

6. Individual and community assessment. Able to provide valuable insights into community problems such as domestic violence.

CHWs, community health workers.

\section{DISCUSSION}

\section{Summary of findings}

In this review, the three main types of CHW interventions to improve preventive care for disadvantaged populations-education, navigation and self-management or combinations of these-were delivered most frequently by mature aged, educated bilingual female CHWs with community experience and training tailored to the intervention. All the studies demonstrated an improvement in at least one outcome-most frequently clinical disease risk indicators, screening rates and change in health behaviours. Navigation interventions tended to have an impact on health service use, whereas education interventions were more likely to result in improvements to patient behaviour. These findings are consistent with systematic reviews of the role of CHW in chronic disease management and navigation to community-based health services. ${ }^{65-67}$ However, these roles represent a narrow range of potential roles for CHWs (text box 2) ${ }^{68}$ Of interest, there is no mention of the clinical preventive roles (eg, monitoring blood pressure, immunisations) that can be seen in underserved settings such as Aboriginal Health Workers in Australia, rural health workers in parts of the USA and maternal and child workers in less developed countries. ${ }^{69-71}$ The expressed roles fit most comfortably with roles $1,2,4$ above but the roles are very situational specific and, in this review, we identify that the focus is on individuals rather than communities and systems. This is evolving into more sophisticated approaches to health education including coaching, social support and use of social media and involvement in research to build an evidence base for CHWs. There is increased focus on building CHWs into multidisciplinary teams for professional support and increased scope to advocate on behalf of their patients as individuals, health consumers and communities.

In Australia, we can see overlapping roles with CHWs being developed, for example, peer workers in mental and drug health, cultural support workers and bilingual community educators as well as specialised nurses providing outreach services in the community. ${ }^{72}$

\section{Enablers and barriers to implementation}

\section{Enablers}

This review found considerable amount of evidence that CHWs, through their close connections to their communities and knowledge of patient's values and circumstances, can improve access to health services and ability to benefit from their programmes. There is an authorising environment to develop a strong CHW workforce that will provide community patient and carer engagement. There is also a need for CHWs to support complex management plans for people with multimorbidity being cared for in the community. The fact that a growing number of studies were undertaken in PHC settings is encouraging as these services are the gateway to the wider health system. Creating entry-level positions is important as health systems try to create a diverse workforce that reflects their local communities.

CHWs performed a wide range of roles including helping patients navigate the healthcare system, being a liaison for healthcare appointments and communication, directing patients to services and helping them access community resources. They serve as health educators, provide and reinforce basic health education on disease prevention and management of chronic disease. They also gather patient self-reported health data for researchers. CHWs training and role development in transdisciplinary practice, patient education, resourcing and navigation support facilitate the implementation of CHWs interventions in $\mathrm{PHC}^{73}$ This is consistent with the literature on the role of CHW and suggests the importance of structural and organisational arrangements to support CHWs. ${ }^{74}$ It is also consistent with implementation science approaches to developing and sustaining programmes across health systems. ${ }^{75}$

\section{Barriers}

Reported barriers include the short duration of interventions being studied, ensuring compliance and high rates of loss to follow-up. CHWs training was an important part of intervention implementation but developing effective models of CHW training and maintaining regular continuing education and team building for CHWs together with other health professionals was challenging.

\section{Limitations of the review}

The generalisability of results of this study is limited by the small number of studies identified in the review and the variation in the methodological quality of the studies. Although mental health preventive interventions were not excluded, it is possible that some may have not been identified by the search terms for preventive care. The methodological quality of the studies was appraised as moderate or weak. The blinding component of the research data collection was not clearly defined in any studies. We did not exclude studies from our analysis based on the quality appraisal results. Although all studies showed some positive intervention effects, we cannot be confident given the quality of many of these. More evidence is also needed on the sustainability of these interventions, as the studies in the review were short duration and generally conducted follow-up at a period of 6 months or less from the end of interventions. 


\section{CONCLUSION}

The evidence generated from this systematic scoping review demonstrates the potential contribution of CHWs to improving access to preventive care for patients from disadvantaged backgrounds. There has been a tendency in the literature to focus on the role of CHWs in providing cultural and linguistic connections. However, there is also a need to develop and build on the scope of practice of CHWs especially in supporting navigation to health services and programmes and providing education to support behaviour change. There is an opportunity to examine which model of education is most effectiveone-on-one or group sessions-and to examine potential additional benefits such as improvements in social connection among participants in group sessions. It is interesting to note that there was no mention in the studies of how other healthcare professionals responded to the role of CHWs. Working among a team of health professionals is likely to be enabling and to capitalise on the contribution this emerging workforce can make. Given that those who are most disadvantaged are less likely to access healthcare, the impact of navigation support on health services use is especially encouraging.

\section{Patient and public involvement}

We did not involve patients or the public in our work.

Acknowledgements This review was conducted at Centre for Primary Health Care and Equity, UNSW. We acknowledge the administrative support provided by the administrative team at CPHCE.

Contributors NS contributed to the design of the review, designed and conducted the search, adjudicated and appraised studies, extracted and analysed data and drafted the manuscript. MH coordinated and designed the review, conducted the search, appraised studies, extracted and analysed data and reviewed the manuscript. EH and JL contributed to the design of the review, adjudicated and appraised studies, reviewed and analysed data and reviewed the manuscript. SKM updated the original search for 2018/2019 and revised the manuscript. All authors read and approved the final manuscript.

Funding The authors have not declared a specific grant for this research from any funding agency in the public, commercial or not-for-profit sectors.

Competing interests None declared.

Patient consent for publication Not required.

Provenance and peer review Not commissioned; externally peer reviewed.

Data availability statement All data relevant to the study are included in the article or uploaded as supplementary information.

Open access This is an open access article distributed in accordance with the Creative Commons Attribution Non Commercial (CC BY-NC 4.0) license, which permits others to distribute, remix, adapt, build upon this work non-commercially, and license their derivative works on different terms, provided the original work is properly cited, appropriate credit is given, any changes made indicated, and the use is non-commercial. See: http://creativecommons.org/licenses/by-nc/4.0/.

ORCID iD

Mark Harris http://orcid.org/0000-0002-0705-8913

\section{REFERENCES}

1 Begg S, Vos T, Barker B, et al. The burden of disease and injury in Australia 2003, 2007

2 Rothman AA, Wagner EH. Chronic illness management: what is the role of primary care? Ann Intern Med 2003;138:256-61.
3 World Health Organization. Global action plan for the prevention and control of noncommunicable diseases 2013-2020. World Health Organization, 2013.

4 Yarnall KSH, Østbye T, Krause KM, et al. Family physicians as team leaders: "time" to share the care. Prev Chronic Dis 2009;6:A59.

5 Ghorob A, Bodenheimer T. Sharing the care to improve access to primary care. N Engl J Med 2012;366:1955-7.

6 Australian Institute of Health and Welfare. Australia's health 2016 (Contract No.: Australia's health series no. 15. Cat. no. AUS 199. Canberra: AlHW, 2016.

7 Caperchione CM, Kolt GS, Mummery WK. Physical activity in culturally and linguistically diverse migrant groups to Western Society: a review of barriers, enablers and experiences. Sports Med 2009;39:167-77.

8 Ali HI, Baynouna LM, Bernsen RM. Barriers and facilitators of weight management: perspectives of Arab women at risk for type 2 diabetes. Health Soc Care Community 2010;18:219-28.

9 Stimpson JP, Wilson FA, Murillo R, et al. Persistent disparities in cholesterol screening among immigrants to the United States. Int $J$ Equity Health 2012;11:22.

10 von Wagner C, Knight K, Steptoe A, et al. Functional health literacy and health-promoting behaviour in a national sample of British adults. J Epidemiol Community Health 2007;61:1086-90.

11 Wolf MS, Gazmararian JA, Baker DW. Health literacy and health risk behaviors among older adults. Am J Prev Med 2007:32:19-24.

12 Berkman ND, Sheridan SL, Donahue KE, et al. Health literacy interventions and outcomes: an updated systematic review (contract No.: evidence Report/Technology Assesment No. 199. Rockville, MD: Agency for Healthcare Research and Quality, 2011.

13 Kobayashi LC, Wardle J, von Wagner C. Limited health literacy is a barrier to colorectal cancer screening in England: evidence from the English longitudinal study of ageing. Prev Med 2014;61:100-5.

14 Peart A, Lewis V, Brown T, et al. Patient navigators facilitating access to primary care: a scoping review. BMJ Open 2018;8:e019252.

15 Starfield B. Primary care: an increasingly important contributor to effectiveness, equity, and efficiency of health services. SESPAS report 2012. Gac Sanit 2012;26:20-6.

16 APHA. Support for community health worker leadership in determining workforce standards for training and credentialing 2014. Available: https://www.apha.org/policies-and-advocacy/ public-health-policy-statements/policy-database/2015/01/28/14/15/ support-for-community-health-worker-leadership

17 WHO EMRO. Health promotion and disease prevention through population-based interventions, including action to address social determinants and health inequity, 2018. Available: http://www. emro.who.int/about-who/public-health-functions/health-promotiondisease-prevention.html

18 Peters MDJ, Godfrey CM, Khalil H, et al. Guidance for conducting systematic scoping reviews. Int J Evid Based Healthc 2015;13:141-6.

19 Samaan Z, Mbuagbaw L, Kosa D, et al. A systematic scoping review of adherence to reporting guidelines in health care literature. $J$ Multidiscip Healthc 2013;6:169.

20 Booth V, Hood-Moore V, Hancox JE, et al. Systematic scoping review of frameworks used to develop rehabilitation interventions for older adults. BMJ Open 2019;9:e024185.

21 Jackson N, Waters E, the Guidelines for Systematic Reviews of Health Promotion and Public Health Interventions Taskforce. The challenges of systematically reviewing public health interventions. $J$ Public Health 2004;26:303-7.

22 Spangaro J, Adogu C, Zwi AB, et al. Mechanisms underpinning interventions to reduce sexual violence in armed conflict: a realistinformed systematic review. Confl Health 2015;9:19.

23 Pawson R. Evidence-based policy: a realist perspective. Sage, 2006.

24 Rycroft-Malone J, McCormack B, Hutchinson AM, et al. Realist synthesis: illustrating the method for implementation research. Implement Sci 2012;7:33.

25 Ethnic Communities' Council of Victoria Inc. Glossary of terms. Victoria: Ethnic Communities' Council of Victoria Inc, 2012. http:// www.eccv.org.au/library/file/document/ECCV_Glossary_of_Terms_ 23_October.docx

26 Shea BJ, Reeves BC, Wells G, et al. AMSTAR 2: a critical appraisal tool for systematic reviews that include randomised or nonrandomised studies of healthcare interventions, or both. BMJ 2017;358:j4008.

27 Armijo-Olivo S, Stiles CR, Hagen NA, et al. Assessment of study quality for systematic reviews: a comparison of the Cochrane collaboration risk of bias tool and the effective public health practice project quality assessment tool: methodological research. J Eval Clin Pract 2012;18:12-18.

28 Balcazar HG, Byrd TL, Ortiz M, et al. A randomized community intervention to improve hypertension control among Mexican 
Americans: using the promotoras de salud community outreach model. J Health Care Poor Underserved 2009;20:1079-94.

29 Balcázar HG, de Heer H, Rosenthal L, et al. A promotores de salud intervention to reduce cardiovascular disease risk in a highrisk Hispanic border population, 2005-2008. Prev Chronic Dis 2010;7:A28.

30 Braschi CD, Sly JR, Singh S, et al. Increasing colonoscopy screening for Latino Americans through a patient navigation model: a randomized clinical trial. $J$ Immigrant Minority Health 2014;16:934-40.

31 DeGroff A, Schroy PC, Morrissey KG, et al. Patient navigation for colonoscopy completion: results of an RCT. Am J Prev Med 2017;53:363-72.

32 Goelen G, De Clercq G, Hanssens S. A community peer-volunteer telephone reminder call to increase breast cancer-screening attendance. Oncol Nurs Forum 2010;37:E312-7.

33 Hoffman HJ, LaVerda NL, Young HA, et al. Patient navigation significantly reduces delays in breast cancer diagnosis in the district of Columbia. Cancer Epidemiol Biomarkers Prev 2012;21:1655-63.

34 Horne HN, Phelan-Emrick DF, Pollack CE, et al. Effect of patient navigation on colorectal cancer screening in a community-based randomized controlled trial of urban African American adults. Cancer Causes Control 2015;26:239-46.

35 Hunter JB, de Zapien JG, Papenfuss M, et al. The impact of a promotora on increasing routine chronic disease prevention among women aged 40 and older at the U.S.-Mexico border. Health Educ Behav 2004;31:18S-28.

36 Jandorf L, Braschi C, Ernstoff E, et al. Culturally targeted patient navigation for increasing African Americans' adherence to screening colonoscopy: a randomized clinical trial. Cancer Epidemiol Biomarkers Prev 2013;22:1577-87.

37 Jandorf L, Cooperman JL, Stossel LM, et al. Implementation of culturally targeted patient navigation system for screening colonoscopy in a direct referral system. Health Educ Res 2013;28:803-15.

38 Kieffer EC, Caldwell CH, Welmerink DB, et al. Effect of the healthy MOMs lifestyle intervention on reducing depressive symptoms among pregnant Latinas. Am J Community Psychol 2013;51:76-89.

39 Koniak-Griffin D, Brecht M-L, Takayanagi S, et al. A community health worker-led lifestyle behavior intervention for Latina (Hispanic) women: feasibility and outcomes of a randomized controlled trial. Int J Nurs Stud 2015;52:75-87.

40 Larkey LK, Herman PM, Roe DJ, et al. A cancer screening intervention for underserved Latina women by lay educators. Journal of Women's Health 2012;21:557-66.

41 Marshall JK, Mbah OM, Ford JG, et al. Effect of patient navigation on breast cancer screening among African American Medicare beneficiaries: a randomized controlled trial. $J$ Gen Intern Med 2016;31:68-76.

42 Percac-Lima S, Ashburner JM, Zai AH, et al. Patient navigation for comprehensive cancer screening in high-risk patients using a population-based health information technology system. JAMA Intern Med 2016;176:930-7.

43 Simmons D, Rush E, Crook N, et al. Development and piloting of a community health worker-based intervention for the prevention of diabetes among New Zealand Maori in te Wai O Rona: diabetes prevention strategy. Public Health Nutr 2008;11:1318-25.

44 Woodruff SI, Candelaria JI, Elder JP. Recruitment, training outcomes, retention, and performance of community health advisors in two tobacco control interventions for Latinos. J Community Health 2010;35:124-34.

45 Molina Y, Kim SJ, Berrios N, et al. Patient navigation improves subsequent breast cancer screening after a noncancerous result: evidence from the patient navigation in medically underserved areas study. J Womens Health 2018;27:317-23.

46 Balcázar H, Alvarado M, Cantu F, et al. A promotora de salud model for addressing cardiovascular disease risk factors in the US-Mexico border region. Prev Chronic Dis 2009;6:A02.

47 Balcazar H, Alvarado M, Ortiz G. Salud para SU Corazon (health for your heart) community health worker model: community and clinical approaches for addressing cardiovascular disease risk reduction in Hispanics/Latinos. J Ambul Care Manage 2011;34:362-72.

48 Balcázar H, Wise S, Rosenthal EL, et al. An ecological model using promotores de salud to prevent cardiovascular disease on the USMexico border: the heart project. Prev Chronic Dis 2012;9:E35.

49 Cruz Y, Hernandez-Lane M-E, Cohello Jl, et al. The effectiveness of a community health program in improving diabetes knowledge in the Hispanic population: Salud Y Bienestar (health and wellness). $J$ Community Health 2013;38:1124-31.
50 Barnes-Boyd C, Fordham Norr K, Nacion KW. Promoting infant health through home visiting by a nurse-managed community worker team. Public Health Nurs 2001;18:225-35.

51 Esperat MC, Flores D, McMurry L, et al. Transformacion para Salud: a patient navigation model for chronic disease self-management. Online J Issues Nurs 2012;17:2.

52 Denman CA, Rosales C, Cornejo E, et al. Evaluation of the Community-Based Chronic Disease Prevention Program Meta Salud in Northern Mexico, 2011-2012. Prev Chronic Dis 2014;11:E154.

53 Kegler MC, Malcoe LH. Results from a lay health advisor intervention to prevent lead poisoning among rural native American children. Am $J$ Public Health 2004:94:1730-5.

54 Mojica CM, Morales-Campos DY, Carmona CM, et al. Breast, cervical, and colorectal cancer education and navigation: results of a community health worker intervention. Health Promot Pract 2016;17:353-63.

55 Parra-Medina D, Morales-Campos DY, Mojica C, et al. Promotora outreach, education and navigation support for HPV vaccination to Hispanic women with unvaccinated daughters. $J$ Cancer Educ 2015;30:353-9.

56 Percac-Lima S, Benner CS, Lui R, et al. The impact of a culturally tailored patient navigator program on cervical cancer prevention in Latina women. J Womens Health 2013;22:426-31.

57 Percac-Lima S, López L, Ashburner JM, et al. The longitudinal impact of patient navigation on equity in colorectal cancer screening in a large primary care network. Cancer 2014;120:2025-31.

58 Staten LK, Cutshaw CA, Davidson C, et al. Effectiveness of the Pasos Adelante chronic disease prevention and control program in a US-Mexico border community, 2005-2008. Prev Chronic Dis 2012:9:E08.

59 Treadwell H, Holden K, Hubbard R, et al. Addressing obesity and diabetes among African American men: examination of a communitybased model of prevention. J Natl Med Assoc 2010;102:794-802.

60 Wells KJ, Rivera MI, Proctor SSK, et al. Creating a patient navigation model to address cervical cancer disparities in a rural Hispanic farmworker community. J Health Care Poor Underserved 2012;23:1712-8.

61 Wilson FA, Villarreal R, Stimpson JP, et al. Cost-Effectiveness analysis of a colonoscopy screening navigator program designed for Hispanic men. J Cancer Educ 2015;30:260-7.

62 Krantz MJ, Beaty B, Coronel-Mockler S, et al. Reduction in cardiovascular risk among Latino participants in a community-based intervention linked with clinical care. Am J Prev Med 2017;53:e71-5.

63 Honeycutt S, Green R, Ballard D, et al. Evaluation of a patient navigation program to promote colorectal cancer screening in rural Georgia, USA. Cancer 2013;119:3059-66.

64 Wagoner KG, Downs M, Alonzo J, et al. Latino men's qualitative perspectives on a lay health advisor intervention to promote their sexual health. Health Soc Care Community 2015;23:304-12.

65 Valaitis RK, Carter N, Lam A, et al. Implementation and maintenance of patient navigation programs linking primary care with communitybased health and social services: a scoping literature review. BMC Health Serv Res 2017;17:116.

66 Mossabir R, Morris R, Kennedy A, et al. A scoping review to understand the effectiveness of linking schemes from healthcare providers to community resources to improve the health and well-being of people with long-term conditions. Health Soc Care Community 2015;23:467-84.

67 Viswanathan M, Kraschnewski JL, Nishikawa B, et al. Outcomes and costs of community health worker interventions: a systematic review. Medical care 2010:792-808.

68 Wiggins N, Borbon A. Core roles and competencies of community health advisors. The Final Full Report of the National Community Health Advisor Study: Weaving the Future Tucson: University of Arizona, Health Sciences Center, 1998.

69 Breedlove G, Lamping B, Smith JA. The Kansas health education training center: caring for the underserved. Kansas Nurse 2006;81.

70 Haines A, Sanders D, Lehmann U, et al. Achieving child survival goals: potential contribution of community health workers. Lancet 2007:369:2121-31.

71 Abbott P, Gordon E, Davison J. Expanding roles of Aboriginal health workers in the primary care setting: seeking recognition. Contemp Nurse 2007;26:66-73.

72 Javanparast S, Windle A, Freeman T, et al. Community health worker programs to improve healthcare access and equity: are they only relevant to low- and middle-income countries? Int J Health Policy Manag 2018;7:943-54.

73 Gunderson JM, Wieland ML, Quirindongo-Cedeno O, et al. Community health workers as an extension of care coordination in primary care: a community-based Cosupervisory model. J Ambul Care Manage 2018;41:333. 
74 Katigbak C, Van Devanter N, Islam N, et al. Partners in health: a conceptual framework for the role of community health workers in facilitating patients' adoption of healthy behaviors. Am J Public Health 2015;105:872-80.
75 Glasgow RE, Chambers D, Robust D. Developing robust, sustainable, implementation systems using rigorous, rapid and relevant science. Clin Trans/ Sci 2012;5:48-55. 